\title{
Retention of alpha Tocopherol and antioxidant activity of encapsulated palm mixed Vitamin $E$ in formulated blends
}

\begin{abstract}
Palm vitamin E containing mixture of tocopherol and tocotrienol was encapsulated using combined solution of maltodextrin and sodium caseinate by spray drying technique. The best formulation that fulfilled the requirement of high core retention with moderate antioxidant activity was found to be $24.5 \%(\mathrm{w} / \mathrm{w})$ of vitamin E concentrate, $18.5 \%(\mathrm{w} / \mathrm{w})$ of maltodextrin and $7 \%(\mathrm{w} / \mathrm{w})$ of sodium caseinate. The corresponding core retention and antioxidant activity value were found to be $71.5 \%$ and $43 \%$, respectively. More than $80 \%$ of encapsulated $\alpha$-tocopherol was stable over the whole range of temperature compared to non-encapsulated $\alpha$-tocopherol. A first-order kinetics model was determined in term of degradation of $\alpha$-tocopherol in non-encapsulated vitamin $\mathrm{E}$ at temperature of $50^{\circ} \mathrm{C}$ and $28^{\circ} \mathrm{C}$ within 42 days of storage. Degradation rate constants $(k)$ were $2.8 \times 10^{-2}$ day $^{-1}$ and $3 \times 10^{-2}$ day $^{-1}$ for $28^{\circ} \mathrm{C}$ and $50^{\circ} \mathrm{C}$, respectively. The half-life determined were 25 days at $28^{\circ} \mathrm{C}$ and 23 days at $50^{\circ} \mathrm{C}$ of storage condition.
\end{abstract}

Keywords: tocopherol, temperature, degradation, microencapsulation, materials, vitamin $\mathrm{E}$
Volume 6 Issue 3 - 2018

\author{
Siti Norina Selamat, ${ }^{1,2}$ Ida Idayu Muhamad,' \\ Zuhaili Idham, ${ }^{3}$ Norhayati Pae' \\ 'Department of Bioprocess Engineering, Universiti Teknologi \\ Malaysia (UTM), Malaysia \\ ${ }^{2}$ Institute of Bioproduct Development, UTM, Malaysia \\ ${ }^{3}$ Centre of Lipid Engineering Applied Research (CLEAR), UTM, \\ Malaysia
}

\begin{abstract}
Correspondence: Ida Idayu Muhamad, Department of Bioprocess Engineering, Faculty of Chemical \& Energy Engineering, Universiti Teknologi Malaysia (UTM) 81310 johor Bahru, Johor, Malaysia, Tel +607-5535577, Fax +607-558I463, Email idaidayu@utm.my
\end{abstract}

Received: December 18, 2016 | Published: May 252018

\section{Introduction}

Palm vitamin E (30\% tocopherols, 70\% tocotrienols) has been extensively researched for its nutritional and health properties, including antioxidant activity, cholesterol lowering, anti-cancer effect and protection against atherosclerosis. These are attributed largely to its tocotrienol content. ${ }^{1}$ However, the utilization of beneficial effects of tocopherol and tocotrienol are limited because these compound is labile to heat and oxygen, when exposed, converted to quinone via epoxide formation. ${ }^{2}$ This problem can be partially overcome by applying microencapsulation technology which is this sensitive ingredient is entrapped in a protective polymer encapsulating agent or wall materials. The technology applied in order to protect vitamin $\mathrm{E}$ from unfavorable environment and to minimize the degree of vitamin E degradation. Besides, the development of encapsulated vitamin E should be fast due to the dynamics of the nutraceutical market. Microencapsulation techniques, such as spray drying, spray chilling, extrusion, coacervation, cocrystallization, and freeze drying; have been widely applied in the food industry for encapsulating vitamins, minerals and other sensitive ingredients. ${ }^{2}$

Spray-drying has been traditionally used for the encapsulation of oil-based vitamins and fatty acids. According to Champagne \& Fustier, ${ }^{3}$ spray-drying of emulsions is generally recommended for the encapsulation of lipid-soluble vitamins (i.e. $\beta$-carotene, vitamin $\mathrm{A}, \mathrm{D}$ and $\mathrm{E})$. In addition, the spray-drying technique has been successfully used for the microencapsulation of bioactive molecules such as enzymes, flavors and drugs. Gouin ${ }^{4}$ reported that spray drying encapsulation has been used in the food industry since the late 1950's to provide flavor oils with some protection against degradation or oxidation and to convert liquid form to powder form. Furthermore, previous studies only concerned with tocopherol and tocotrienol stability during storage after food processing of various products: $\alpha-$ tocopherol in milk-based infant formulas according to Miquel et al..$^{5}$ and tocopherols content in spray-dried whole egg according to Caboni et al. ${ }^{6}$ Some studies had also been reported the loss of tocopherol and tocotrienol during heat treatment such as broiling, roasting, frying, boiling in various types of meat and legumes, ${ }^{7}$ and deep-fat frying of French fries using refined vegetable oils. ${ }^{8}$ However, there is lack of information on the effect of heat treatment to tocopherol and tocotrienol stability in palm vitamin $\mathrm{E}$ after spray drying. Thus, this research focuses on palm vitamin $\mathrm{E}$ as bioactive compound that will be encapsulated by spray drying technique.

Generally, it has previously reported that tocopherol microencapsulated use hydrophobic matrices as waxes and oils due to its lipophilic properties. ${ }^{9}$ In this study, the combination of maltodextrin (DE 11-15) and sodium caseinate was used as wall materials for encapsulation of vitamin E. These wall materials have been chosen in order to obtain hydrosoluble particles of vitamin $\mathrm{E}$ powder. Maltodextrin is considered as good encapsulating agents because it exhibits low viscosities at high solids contents and good solubility. In addition, maltodextrin has high water solubility up to $75 \%$ as reported by Turchiuli et al. ${ }^{10}$ However, it has been reported lack the interfacial properties required for high microencapsulation efficiency and generally associated with other encapsulating materials such as proteins or gums. ${ }^{11}$ Therefore, sodium caseinate in this study was used as emulsifier and stabilizer in association with maltodextrin. In this combination, the carbohydrates provide structure through glass formation whereas the proteins provide emulsification and film forming properties.

The objective of this work was to develop the formulation of blend of maltodextrin and sodium caseinate which has higher core retention and possess of antioxidant role in spray dried palm vitamin $\mathrm{E}$ i.e. tocopherol and tocotrienol. 


\section{Materials and methods}

\section{Materials}

Fully Natural Palm Mixed tocotrienols and Tocopherol Concentrate (Food grade) was purchased from Super Vitamins Sdn. Bhd. (Masai, Johor). Maltodextrin (Food Grade, Merck KGaA, Germany) and Sodium Caseinate (Food Grade, Merck KGaA, Germany) were used as carrier agents. HPLC grade analytical reagents used were hexane (Merck, Germany), methanol (Fisher Scientific, USA) and acetonitrile (Fisher scientific, USA). D- $\alpha$-tocopherol standard was purchased from Across Organics, USA.

\section{Methods}

\section{Encapsulation of palm vitamin $\mathbf{E}$}

Before entering the spray dryer, the mixture of Palm vitamin $\mathrm{E}$ concentrate, sodium caseinate and maltodextrin were homogenized for 30minutes using homogenizer (Heidolph, DIAX900, Germany) to form the emulsion (oil in water). Next, spray drying process was performed in Pilot Plant scale Spray Dryer PSD-00 (Hemray Enterprise, Bombay, India) with $1.5 \mathrm{~mm}$ diameter nozzle. The mixture was fed into the main chamber and the feed flow rate was controlled at $10 \mathrm{ml} / \mathrm{min}$. Compressor air pressure was $55 \mathrm{kgf} / \mathrm{cm}$ and atomizer speed was at range $20,000-25,000 \mathrm{rpm}$. The drier was operated at $110^{\circ} \mathrm{C}$ for inlet temperature and $100^{\circ} \mathrm{C}$ for outlet temperature.

\section{Experimental design}

The D-optimal design of Mixture Design technique in DesignExpert Software version $6.0^{12}$ was used to determine the best formulation in term of vitamin $\mathrm{E}$ concentrate, maltodextrin and sodium caseinate for encapsulation process. Palm mixed vitamin $\mathrm{E}$ concentrate was used as a core material. Ten design of experiment were developed based on the identified maximum and minimum value from the preliminary experiments. The formulations designed were shown in Table 1.

Table I 10 formulations developed by Mixture Design Technique using Doptimal design in Design-Expert Software version 6.0

\begin{tabular}{llll}
\hline Run & $\begin{array}{l}\text { Maltodextrin } \\
\%(w / w)\end{array}$ & $\begin{array}{l}\text { Sodium } \\
\text { caseinate } \%(w / w)\end{array}$ & $\begin{array}{l}\text { Palm vitamin E } \\
\text { concentrate\%(w/w) }\end{array}$ \\
\hline 1 & 24 & 7 & 19 \\
2 & 18.5 & 9 & 22.5 \\
3 & 21.25 & 7 & 21.75 \\
4 & 21.25 & 8 & 20.75 \\
5 & 21.25 & 9 & 19.75 \\
6 & 19.88 & 8 & 22.13 \\
7 & 22.63 & 8.5 & 18.88 \\
8 & 24 & 8 & 18 \\
9 & 18.5 & 7 & 24.5 \\
10 & 24 & 9 & 17 \\
\hline
\end{tabular}

\section{Analysis of vitamin E concentration}

The analysis was conducted on the encapsulated vitamin E immediately after spray drying process and after storage condition up to 3 months. Both samples i.e, encapsulated and non-encapsulated vitamin E $(2.0 \mathrm{mg})$ were extracted with $1 \mathrm{ml}$ of hexane and vortexed for 1minute, followed by centrifugation at 3000rpm for 10minutes. After phase separation, the liquid phase containing the tocopherol was collected and filtered through $0.45 \mu \mathrm{m}$ polytetrafluoroethylene (PTFE) membrane prior to injection to the HPLC. About $10 \mu \mathrm{L}$ were injected into a HPLC. Initial of vitamin E value was determined prior to storage to calculate the core retention percentages.

For the storage stability, the best sample determined from the core retention percentages was transferred to Falcon tubes to isolate from air and light. The samples were stored up to 3 months in an incubator in three set of temperature. ${ }^{59}$ First set of samples were kept at room temperature with a temperature range between $28-32^{\circ} \mathrm{C}$. Second set of samples was heated in an oven at $50^{\circ} \mathrm{C}$ and finally another set of samples was refrigerated at a temperature range between 0 to $5^{\circ} \mathrm{C}$. Samples were kept for 60days and were analyzed from zero day (upon spray drying process) and every 7day interval according to the method of Farias et al. ${ }^{13}$ with minor modifications. The HPLC analyses were made in duplicate.

\section{HPLC condition}

Quantitative determination of $\alpha$-tocopherol was made by slightly modifying the method proposed by Aoun et al. ${ }^{14}$ In particular, $\alpha-$ tocopherol was determined by means of an HPLC (Waters model 515, Germany). The column used is Synergy $4 \mathrm{u}$ hydro-RP 80A column $(4 \mu \mathrm{m}, 250 \mathrm{x} 4.6 \mathrm{~mm})$, while the mobile phase is methanol:acetonitrile $(1: 1 \mathrm{v} / \mathrm{v})$. The flow rate was maintained at $1.0 \mathrm{ml} / \mathrm{min}$ and the column temperature was set at $40^{\circ} \mathrm{C}$. The detection was made at a wavelength of $292 \mathrm{~nm}$. Standard reference used is $\alpha$-tocopherol. Data acquisition and processing were performed using the CSW Switch software. Total concentration of $\alpha$-tocopherol was expressed as vitamin E concentration $(\mathrm{mg} / \mathrm{ml})$.

\section{DPPH radical-scavenging assay}

The stable radical 2, 2-diphenyl-1-picrylhydrazyl (DPPH) was used in DPPH radical-scavenging assay. The antioxidant activity was evaluated through the effect of vitamin $\mathrm{E}$ on its capability of scavenging 2, 2-diphenyl-1-picrylhydrazyl (DPPH) radical according to the method of Burits \& Bucar ${ }^{15}$ with minor modifications. It was detected by spectrophotometrically measuring the disappearance of DPPH radical. Fifty $\mu \mathrm{L}$ of $1 \mathrm{mg} / \mathrm{ml}$ concentration of the extracts in ethanol was added to $5 \mathrm{ml}$ of a $0.004 \%$ ethanol solution of DPPH. It was incubated 30minutes in the dark at room temperature. The absorbance was then read at $517 \mathrm{~nm}$ with a UV-VIS spectrophotometer (Lambda 25, Perkin Elmer, USA) against ethanol without DPPH radical as the blank reference. DPPH solution and synthetic antioxidant; butylated hydroxyanisole (BHA) diluted in ethanol was used as negative and positive control, respectively. Each sample was assayed in duplicate. Absorbance was converted to the DPPH radical-scavenging rate according to the equation in equation 1 . This equation used to represent the antioxidant activity of vitamin E. DPPH radical scavenging rate $(\%)$ :

$$
\left[\left(A_{\text {control }}-A_{\text {sample }}\right) / A_{\text {control }}\right] \times 100
$$

where $\mathrm{A}_{\text {control }}$ is the absorbance of DPPH solution (as negative control) and $\mathrm{A}_{\text {sample }}$ is the absorbance of samples.

\section{Statistical analysis}

The statistical analysis was performed using ANOVA included in Design Expert software version 6.0 and $\mathrm{p}<0.05$ was considered to be significant. The results are shown as mean \pm standard error of mean. 


\section{Result and discussion}

\section{Response of sample analysis}

\section{Retention of core material}

Two responses i.e core retention and radical-scavenging activity were analyzed in order to evaluate the optimum value of mixture. Table 2 list the results of the responses for the ten formulations developed. Results showed that the tocopherol remained in the powder after spray-drying was about $51.2 \pm 0.020 \%$ to $71.5 \pm 0.027 \%$, respectively showed that the recovery of tocopherol after spray drying was less than $80 \%$ from the initial content. The best core retention was observed in Run 9 (24.50\% palm vitamin E concentrate, $18.50 \%$ maltodextrin and $7.00 \%$ sodium caseinate).

Table 2 Core retention and antioxidant activity obtained in the phase 2 experiments

\begin{tabular}{llll}
\hline Run & $\begin{array}{l}\text { Core/wall } \\
\text { ratio(CWR) }\end{array}$ & $\begin{array}{l}\text { Response 1: Core } \\
\text { retention(\%) }\end{array}$ & $\begin{array}{l}\text { Response 2: } \\
\text { Radical-scavenging } \\
\text { activity(\%) }\end{array}$ \\
\hline 1 & 0.61 & $59.9 \pm 0.017$ & $39.3 \pm 0.149$ \\
2 & 0.82 & $62.9 \pm 0.006$ & $41.1 \pm 0.119$ \\
3 & 0.77 & $60.3 \pm 0.004$ & $41.5 \pm 0.230$ \\
4 & 0.71 & $63.9 \pm 0.012$ & $44.8 \pm 0.390$ \\
5 & 0.65 & $60.1 \pm 0.020$ & $40.9 \pm 0.231$ \\
6 & 0.79 & $61.5 \pm 0.042$ & $42 \pm 0.233$ \\
7 & 0.6 & $58.5 \pm 0.018$ & $45.9 \pm 0.253$ \\
8 & 0.56 & $57.6 \pm 0.021$ & $39.9 \pm 0.253$ \\
9 & 1 & $71.5 \pm 0.027$ & $43 \pm 0.346$ \\
10 & 0.52 & $51.2 \pm 0.020$ & $30.2 \pm 0.227$ \\
\hline
\end{tabular}

The core retention also influenced by the choice of encapsulation materials as well as the study of the various types of molecular interactions; water/wall, water/core, and wall/core. ${ }^{11}$ Type of wall materials is important to determine the suitability of its function towards the core retention. Previous researchers demonstrated the use of maltodextrin in reducing oxidative degradation of carotenes during storage depending on the concentration of maltodextrin, the level of hydrolysis of the maltodextrin, and drying technique. ${ }^{11,16}$ For the current formulation, the combination of carbohydrate and protein is proven to be effective i.e. maltodextrin is chosen for preventing oxidation of tocopherol whereas sodium caseinate functions as stabilizer and emulsifier for the whole encapsulation process. This is in agreement with previous study by Gharsallaoui et al. ${ }^{11}$

Retention of tocopherol content in the microcapsules for all formulation were significantly increased $(\mathrm{P}<0.05)$ with the increased of core/wall ratio from 0.5 to 1.0. This may suggest that, the higher oil content in the emulsion, the higher percentage of tocopherol remained in the microcapsules. Furthermore, previous study indicated that the core retention were mainly determined by the solids concentration which can only be obtained by increasing the solids concentration resulting higher core material loads to be encapsulated. ${ }^{17}$ Perhaps, the increase of core retention was caused by the increase of solids concentration. Similar results were reported by Rosenberg \& Kopelman. ${ }^{18}$

\section{Antioxidant value}

From the previous study, the antioxidant activity of vitamin E has been successfully determined in crude oils by Ramadan et al. ${ }^{19}$ in refined vegetable oils i.e, palm oil, palm super olein, olive oil and sunflower oil by Rossi et al. ${ }^{8}$ but little is known about encapsulated oils. ${ }^{20}$ Antioxidant activity can be evaluated as total free radicalscavenging capacity, by spectrophotometrically measuring the disappearance of the free 2,2-diphenyl-1-picrylhydrazyl (DPPH) radical. Thus, both encapsulated and non-encapsulated vitamin $\mathrm{E}$ was subjected to screening for their possibility of antioxidant activity by antioxidant assays namely DPPH radical scavenging assay. In this study, DPPH radical was used as a substrate to evaluate the free radical scavenging activity of palm mixed vitamin $\mathrm{E}$ concentrate. The antioxidant properties were evaluated through the effects of vitamin E on their capability to scavenge 2, 2-diphenyl-1-picrylhydrazyl (DPPH) radical and observed spectrophotometrically. It is measured from the bleaching of purple coloured ethanol solution of DPPH. ${ }^{21}$

The best radical-scavenging activity was observed in Run 7 (18.88\% palm vitamin $\mathrm{E}$ concentrate, $22.63 \%$ maltodextrin and $8.50 \%$ sodium caseinate). This is an agreement with Rosenberg et al. ${ }^{17}$ whom reported that in some cases i.e. ethyl butyrate retention was only slightly affected by the initial ester concentration. Furthermore, the moderate radical-scavenging activity obtained which showed the antioxidant property of palm mixed vitamin $\mathrm{E}$ also influenced by the vitamin E concentration loaded. As shown in Table 2, the radicalscavenging activity of encapsulated vitamin $\mathrm{E}$ obtained in this study ranged from $30.2 \pm 0.227 \%$ to $45.9 \pm 0.253 \%$. This result was acceptable based on the studies by Rossi et al. ${ }^{8}$ reported that palm oil had lower antioxidant activity than the palm super olein, the oils richest in tocopherol and tocotrienol. In addition, they also reported that the radical-scavenging activity proved to be significantly correlated with the total content of tocopherol and tocotrienol.

In this study, antioxidant activity of encapsulated vitamin $\mathrm{E}$ in the microcapsules for all formulation showed at the same rate $(\mathrm{P}>0.05)$ with the increased of core/wall ratio (CWR) from 0.5 to 1.0 in all formulations of Run 1 to Run 10. In addition, the previous research by Yoshida et al..$^{22}$ reported that there is some difficulty in evaluating the antioxidant activity of vitamin E (tocopherol and tocotrienol) adequately. This is because antioxidant activity is frequently influenced by their concentration, the types of oils and fats used as substrates, and the method of evaluation. Besides, the antioxidant activity also depends on the polarity of the extracting solvent, the purity of active compounds, as well as the test system. ${ }^{23}$

Figure 1 shows vitamin $\mathrm{E}$ from palm mixed vitamin $\mathrm{E}$ concentrate possessed some antioxidant property about $22.4 \%$ as compared to the synthetic antioxidant, i.e, BHA which had $95.3 \%$ of antioxidant activity. Besides, as reported by Simonne \& Eitenmiller, ${ }^{24}$ tocopherols and tocotrienols seem to degrade more quickly in the oils with high saturated fatty acid content. Actually, in the case of oils containing higher levels of polyunsaturated fatty acids, the double bonds which determine unsaturation compete with the tocopherols and tocotrienols as substrates for oxidation, determining a less rapid decrease of these antioxidants. Instead, in the case of oils low in polyunsaturated fatty acids, tocopherols and tocotrienols constitute the substrates that more easily react with oxygen. However, palm oil has saturated and unsaturated fatty acids in approximately equal amounts. Most of the fatty acids are present as triglycerides. ${ }^{1}$ Therefore, in this study, the antioxidant property of palm vitamin E maybe contributed by the 
tocotrienols instead of tocopherols content in the palm mixed vitamin E concentrate. As reported by Sundram et al. ${ }^{1}$ indicated that palm vitamin $\mathrm{E}$ consists of $30 \%$ of tocopherols and $70 \%$ of tocotrienols. Furthermore, several in vitro and in vivo studies have shown that tocotrienol is a more potent antioxidant than $\alpha$-tocopherol. ${ }^{25,26}$ In addition, it is reported that $\alpha$-tocopherol has the lowest antioxidant activity, even though its biological activity, as vitamin E, is the greatest whereas $\gamma$-tocotrienol has the highest antioxidant activity. ${ }^{27}$ This property of tocotrienols is believed to be related to the presence of an unsaturated side chain, which can more easily be incorporated into cells, and higher recycling efficiency from chromoxyl radicals. ${ }^{26}$ Indeed, since the mechanism of the radical-scavenging reaction of tocopherols and tocotrienols requires that they lose their mobile hydrogen atoms in the hydroxyl group, forming more stable free radicals than those of the fatty acids, it follows that a faster oxidation of tocopherols and tocotrienols corresponds to a greater antioxidant power. ${ }^{28}$ However, tocopherols $(\alpha-, \beta-, \gamma-$ and $\delta-T)$ are naturally occurring lipid antioxidants that specifically inhibit the oxidation of polyunsaturated fatty acids. Furthermore, the tocopherols and tocotrienols are also antioxidants, which contribute to the stability of palm oil. ${ }^{1}$

In addition, vitamin $\mathrm{E}$ in its antioxidant role protects the fatty components of a food or tissue from oxidation by combining with free radicals, and stopping the chain reaction by which free radical multiply. However, while protecting the fat, tocopherols and tocotrienols are generally themselves first oxidized to quinines and dimers. ${ }^{28}$ Therefore, this reaction maybe contributed to the depleted of tocopherols and tocotrienols content which gave least antioxidant activity of palm vitamin $\mathrm{E}$ as compared to the BHA. It is because the DPPH radical scavenging assay showed the existence of a direct correlation between the radical-scavenging capacity of the oils and the total content of natural tocopherols and tocotrienols.

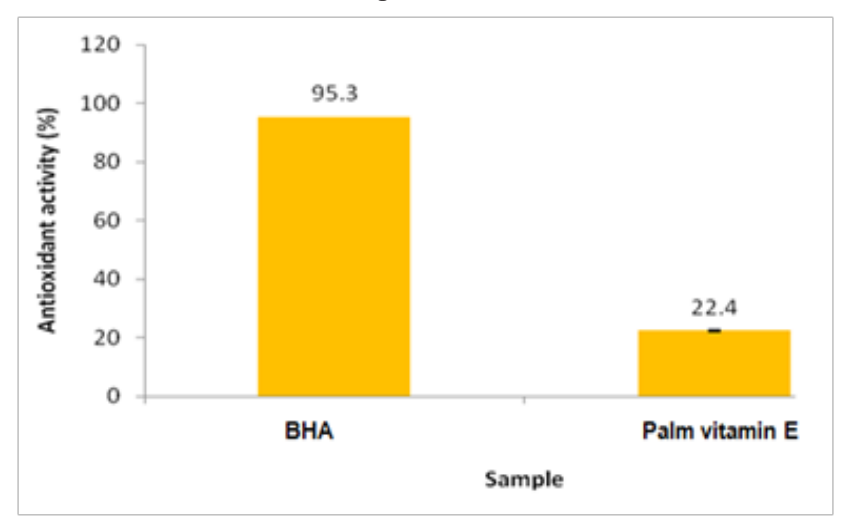

Figure I Antioxidant activity of non-encapsulated palm vitamin E compared to synthetic antioxidant (BHA) tested using DPPH radical scavenging assay. Bars indicate the standard error of mean (SEM) of duplicate analyses $(n=2)$.

Furthermore, the stability of the different homologues of the natural tocopherols and tocotrienols present in the refined vegetable oils basically depends on two factors: the oxidizability of the oil, which is connected with the polyunsaturated fatty acid content, and the kind of tocopherolic compounds present. Although palm oil is relatively resistant to oxidative deterioration due to the low levels of polyunsaturation, tocopherols still remain as useful natural antioxidants and their loss during processing must be minimized..$^{29}$ In particular, tocopherols and tocotrienols, acting as radical scavengers, play an important antioxidant role, since the presence of other antioxidants is negligible. The more oxidizable the oil, on the basis of fatty acid composition, the more stable is the natural tocopherols and tocotrienols present in the oil. As regards the effect of the different tocopherolic compounds, the presence of $\gamma-\mathrm{T} 3$ preserves the other homologues, in particular $\alpha-\mathrm{T}$, with which the greatest vitamin $\mathrm{E}$ activity is associated.

\section{Storage stability}

The best core retention was observed in Run 9 (24.50\% palm vitamin E concentrate, $18.50 \%$ maltodextrin and $7.00 \%$ sodium caseinate). Next, effect of storage temperatures on the stability of encapsulated $\alpha$-tocopherol in the blends of maltodextrin and sodium caseinate from Run 9 was compared with non-encapsulated sample after 28days (4weeks) of storage period as shown in Figure 2. More than $80 \%$ of encapsulated $\alpha$-tocopherol was stable over the whole range of temperature compared to non-encapsulated $\alpha$-tocopherol. However, storage temperature at $28^{\circ} \mathrm{C}$ showed the highest retention of $\alpha$-tocopherol content in non-encapsulated sample among the three temperatures of storage. Below than ambient temperature, the degradation of $\alpha$-tocopherol was increased with the decrease in storage temperature, and it may be due to the retrogation of ingredients in wall material in response to the temperature down as reported by Shamai et al..$^{30}$ for retrogation of waxy corn starch.

Furthermore, more than $65 \%$ of $\alpha$-tocopherol was loss in nonencapsulated vitamin $\mathrm{E}$ after 28days of storage at temperature of $50^{\circ} \mathrm{C}$ as shown in Figure 2. This result indicated a possible chemical instability of $\alpha$-tocopherol in non-encapsulated vitamin $\mathrm{E}$ as reported by Farias, et al. ${ }^{13}$ Perhaps, the degradation of $\alpha$-tocopherol content at temperature of $50^{\circ} \mathrm{C}$ could be reduced by encapsulation process since the $\alpha$-tocopherol showed more stable in encapsulated sample compared to non-encapsulated. It was proven since the encapsulated $\alpha$-tocopherol showed about $17 \%$ of reduction in $\alpha$-tocopherol content compared to non-encapsulated $\alpha$-tocopherol in 28days of storage. According to Chang et al. ${ }^{9}$ the destruction of microcapsules above ambient temperature was supposed to be due to the thermal degradation of wall material.

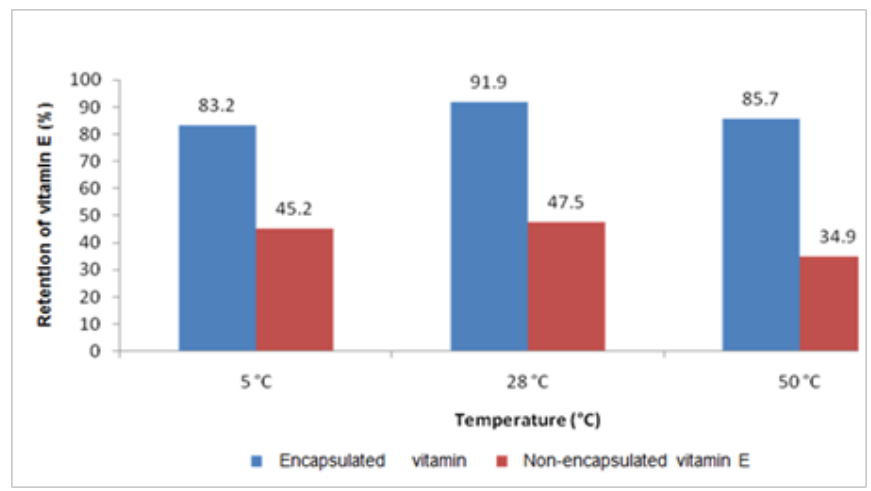

Figure 2 Effect of temperatures on the 28-day storage stability of nonencapsulated and encapsulated of vitamin E. [Notes: error bars cannot be represented in the graph since the SEM was too small].

Besides, about $91.9 \pm 0.021 \%$ of $\alpha$-tocopherol was retained in the microcapsules after 4weeks of storage in ambient temperature. The contents of non-encapsulated $\alpha$-tocopherol also showed higher content in ambient temperature than the refrigerated sample at $5^{\circ} \mathrm{C}$ after 4 weeks. These results indicated that the ambient temperature 
could be adapted for the long-term storage of both non-encapsulated and encapsulated $\alpha$-tocopherol. In contrast with Chandrasekaram et al. ${ }^{31}$ this suggested that these phytonutrients in non-encapsulated form should always be refrigerated and stores in cold, dry places to prevent their loss in concentration. Furthermore, in previous study it is reported the oxidative degradation of tocopherol during storage after 12 months reported a $60-80 \%$ decrease at room temperature and a $28-40 \%$ loss at $20^{\circ} \mathrm{C} .32$

Other than that, the losses of $\alpha$-tocopherol during storage could be due to oxidation by atmospheric oxygen, which might have penetrated into the microcapsules through cracks. ${ }^{33}$ On the other hand, the properties of maltodextrin as wall material could be contributed to the degradation of $\alpha$-tocopherol during storage. It was reported that maltodextrin with a higher DE, or degree of hydrolysis gave better oxidative protection than lower DE maltodextrin. ${ }^{34}$ Perhaps, the maltodextrin with DE $11-15$ used in this study may not have sufficiently protected the $\alpha$-tocopherol from oxidation during the storage time prior to testing.

\section{Kinetics study of degradation of $\alpha$-tocopherol}

The kinetics of degradation of $\alpha$-tocopherol was monitored for both non-encapsulated vitamin $\mathrm{E}$ and encapsulated vitamin $\mathrm{E}$ during storage at $28^{\circ} \mathrm{C}$ and at $50^{\circ} \mathrm{C}$ for 42 days. Reaction orders and rate constants were determined. Figure $4 \& 5$ show the natural logarithm of the percentage retention versus time (days) for non-encapsulated vitamin $\mathrm{E}$ and encapsulated vitamin $\mathrm{E}$, respectively.

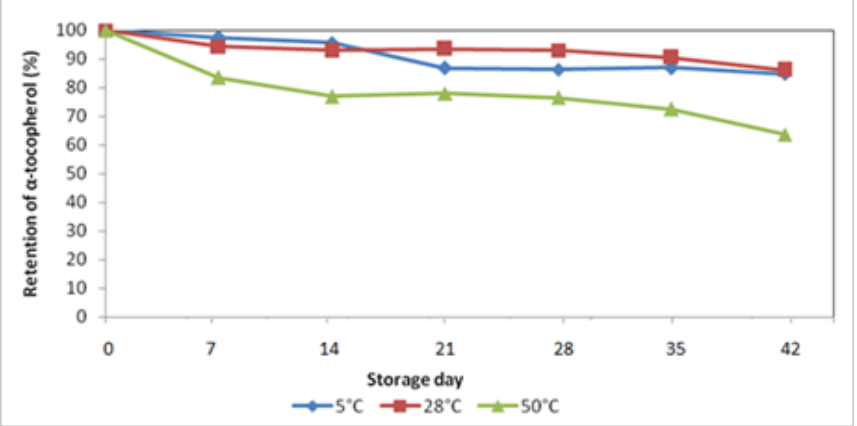

Figure 3 Stability of $\alpha$-tocopherol stored at different temperature up to 42 days. Each point represents an average of duplicate experiments at each temperature. [Notes: error bars cannot be represented in the graph since the SEM was too small].

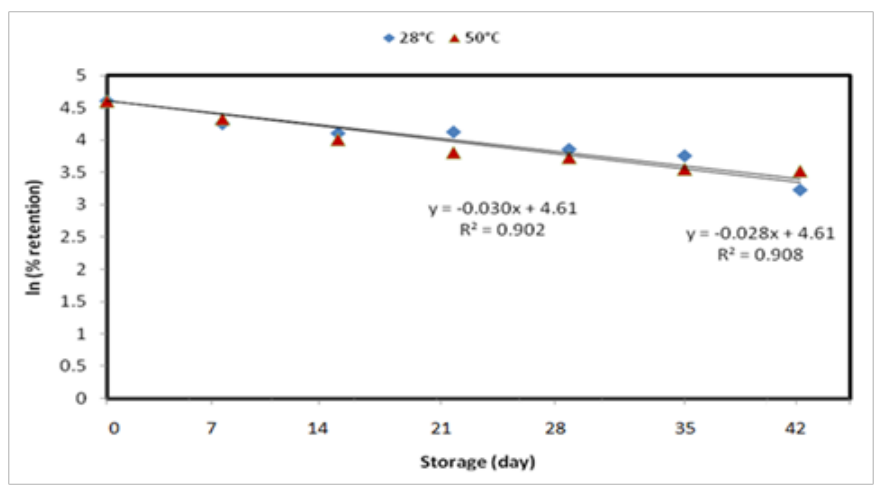

Figure 4 First-order degradation plots for $\alpha$-tocopherol in non-encapsulated vitamin E. Each point represents an average of duplicate experiments at room temperature and $50^{\circ} \mathrm{C}$. [Notes: error bars cannot be represented in the graph since the SEM was too small].

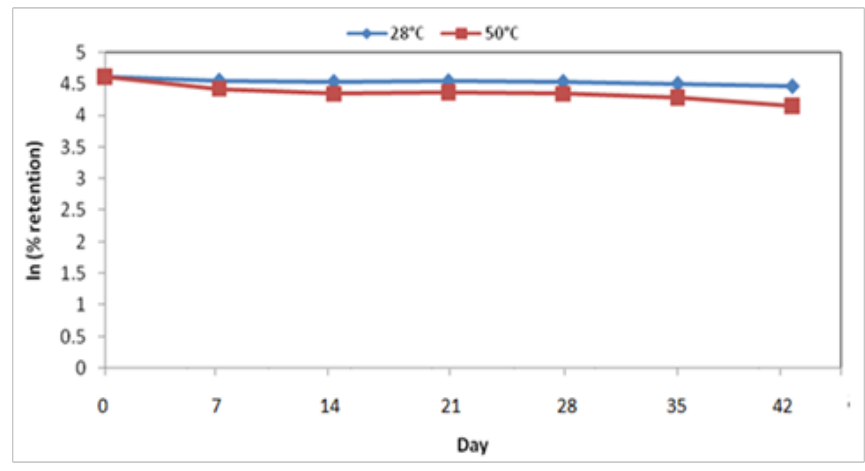

Figure 5 Stability of $\alpha$-tocopherol in microcapsule at different temperature up to 42 days. Each point represents an average of duplicate experiments at each temperature. [Notes: error bars cannot be represented in the graph since the SEM was too small].

$\alpha$-Tocopherol decreased with the function of time and temperature. The degradation of $\alpha$-tocopherol follows the first-order behavior for the non-encapsulated samples for both temperatures studied as shown in Figure 4. This is in agreement with previous study reported by Hidalgo et al. ${ }^{32}$ The correlation coefficient was used as a parameter to determine the reaction order. Degradation rate constants $(k)$ were $\left(2.8 \times 10^{-2}\right.$ day $\left.^{-1}\right)$ and $\left(3 \times 10^{-2}\right.$ day $\left.^{-1}\right)$ for $28^{\circ} \mathrm{C}$ and $50^{\circ} \mathrm{C}$, respectively (Table 3). These values were obtained from the slope of a plot of the natural $\log$ of the percentage retention of $\alpha$-tocopherol versus time (days) as in agreement with Robert et al. ${ }^{34}$

Table 3 Linear mathematical equations represented degradation of vitamin $E$ content in non-encapsulated vitamin $E$ and rate constant for both temperatures

\begin{tabular}{lllll}
\hline Temperature & Equation & $\mathbf{R}^{2}$ & $\begin{array}{l}\text { Rate } \\
\text { constant (k) }\end{array}$ & $\begin{array}{l}\mathbf{t}_{1 / 2} \\
(\text { days })\end{array}$ \\
\hline $28^{\circ} \mathrm{C}$ & $y=-0.028 x+4.6 \mathrm{I}$ & 0.908 & $2.8 \times 10^{-2} \mathrm{day}^{-1}$ & 25 \\
$50^{\circ} \mathrm{C}$ & $y=-0.03 x+4.6 \mathrm{I}$ & 0.902 & $3 \times 10^{-2}$ day $^{-1}$ & 23 \\
\hline
\end{tabular}

An increase in storage temperature led to an increase in the rate constant $(k)$ for $\alpha$-tocopherol indicating a quicker degradation of the compounds. Similar results were observed reported by Hidalgo et al. ${ }^{32}$ For a first-order reaction in this study, the half-life was determined at a specific temperature by the equation $t_{1 / 2}=\ln 2 / k$ as shown in Table $3 .{ }^{34}$

Furthermore, there are few studies available on degradation kinetics of tocopherol were reported. First-order kinetics were observed in a model system containing $\alpha$-tocopherol kept between 20 and $37^{\circ} \mathrm{C},{ }^{35}$ in a model system of $\alpha-\mathrm{T}, \gamma-\mathrm{T}, \delta-\mathrm{T}$ and glycerol during high temperature treatments; ${ }^{36,37}$ in rice bran extruded at temperatures between 100 to $140^{\circ} \mathrm{C},{ }^{38}$ in a composting system, ${ }^{39}$ in extra-virgin oil kept at 25 and $40^{\circ} \mathrm{C}$ for eight months, ${ }^{40}$ in extra-virgin oil stored at $30^{\circ} \mathrm{C}$ for six months..$^{41}$

In addition, the results also indicate that storing vitamin $\mathrm{E}$ under refrigeration or at temperatures not exceeding $20^{\circ} \mathrm{C}$ can better preserved their tocopherol and tocotrienol contents ${ }^{32}$ which are considered for non-encapsulated vitamin E. Both temperatures showed rapid degradation of tocopherol since the half-life determined were 25 days and 23 days at room temperature and $50^{\circ} \mathrm{C}$ of storage condition. However, Figure 5 showed that $\alpha$-tocopherol in microcapsules did not fit the first-order kinetics as compared to nonencapsulated $\alpha$-tocopherol. Hence, it is proven that the encapsulated $\alpha$-tocopherol showed stability in stored for both room temperature 
and $50^{\circ} \mathrm{C}$. This is in agreement with the previous discussion on retention of $\alpha$-tocopherol in encapsulated vitamin $\mathrm{E}$.

\section{Conclusion}

Encapsulation of palm mixed vitamin E concentrate has been successfully developed using maltodextrin and sodium caseinate as wall materials. More than $80 \%$ of encapsulated $\alpha$-tocopherol was stable over the whole range of temperature compared to non-encapsulated $\alpha$-tocopherol. Non-encapsulated $\alpha$-tocopherol fit the first-order kinetics in degradation study at temperature of $50^{\circ} \mathrm{C}$ and $28^{\circ} \mathrm{C}$ within 42 days of storage. Degradation rate constants $(k)$ were $2.8 \times 10^{-2}$ day $^{-1}$ and $3 \times 10^{-2}$ day $^{-1}$ for $28^{\circ} \mathrm{C}$ and $50^{\circ} \mathrm{C}$, respectively. Both temperatures showed rapid degradation of non-encapsulated $\alpha$-tocopherol since the half-life determined were 25 days and 23 days at $28^{\circ} \mathrm{C}$ and $50^{\circ} \mathrm{C}$ of storage condition, respectively. Thus, it is recommended that the study will be further on the optimization process of feed formulation in order to develop the stable encapsulated vitamin $\mathrm{E}$ with higher antioxidant values.

\section{Acknowledgements}

The authors gratefully thank the Institute of Bioproducts Development (IBD), Universiti Teknologi Malaysia, Skudai for the financial support through bioentrepreneur program.

\section{Conflict of interest}

The authors declare that there is no conflict of interest.

\section{References}

1. Sundram K, Sambanthamurthi R, Tan YA. Palm Fruit Chemistry and Nutrition. Asia Pacific Journal Clinical Nutritional. 2003;12(3):355-362.

2. Yoo SH, Song YB, Chang PS, et al. Microencapsulation of $\boldsymbol{\alpha}$ tocopherol using Sodium Alginate and its Controlled Release Properties. International Journal of Biological Macromolecules. 2006;38(1);25-30.

3. Champagne CP, Fustier P. Microencapsulation for the Improved Delivery of Bioactive Compounds into Foods. Current Opinion in Biotechnology. 2007;18(2):184-190.

4. Gouin S. Micro-encapsulation: Industrial Appraisal of Existing Technologies and Trends. Trends in Food Science and Technology. 2004;15(7-8):330-347.

5. Miquel E, Alegria A, Barbera R, et al. Stability of Tocopherols in Adapted Milk-Based Infant Formulas during Storage. International Dairy Journal. 2004;14(11):1003-1011.

6. Caboni MF, Boselli E, Messia MC, et al. Effect of Processing and Storage on the Chemical Quality Markers of Spray-Dried Whole Egg. Food Chemistry. 2005;92(2):293-303.

7. Leskova E, Kubikova J, Kovacikova E, et al. Vitamin Losses: Retention during Heat Treatment and Continual Changes Expressed by Mathematical Models. Journal of Food Composition and Analysis. 2006;19(4):252-276

8. Rossi M, Alamprese C, Ratti S. Tocopherols and Tocotrienols as Free Radical-Scavengers in Refined Vegetables Oils and Their Stability during Deep-Fat Frying. Food Chemistry. 2007;102(3):812-817.

9. Chang PS, Lee JH, Lee JH. Development of a New Colorimetric Method Determining the Yield of Microencapsulation of $\boldsymbol{\alpha}$-tocopherol. Journal of Agricultural and Food Chemistry. 2005;53(19):7385-7389.
10. Turchiuli C, Fuchs M, Bohin M, et al. Oil encapsulation by spray drying and fluidized bed agglomeration. Innovative Food Science and Emerging Technologies. 2005;6(1):29-35.

11. Gharsallaoui A, Roudaut G, Chambin O, et al. Applications of SprayDrying in Microencapsulation of Food Ingredients: An Overview. Food Research International. 2007;40(9):1107-1121.

12. Stat-Ease, Inc. Design Expert (Version 6.0) Software, USA; 2002. p. $1-6$.

13. Farias MC, Moura ML, Andrade L, et al. Encapsulation of the AlphaTocopherol in a Glassy Food Model Matrix. Materials Research. 2007;10(1):57-62.

14. Aoun E, Rima J, Chidiac G, et al. High-Performance Liquid Chromatographic and Spectrofluorometric Determination of $\boldsymbol{\alpha}-$ tocopherol in a Natural Plant: Ferula hermonis (Zalooh Root). Journal of Food Composition and Analysis. 2005;18(7):607-615.

15. Burits M, Bucar F. Antioxidant Activity of Nigella sativa Essential Oil Phytotheraphy Research. 2000;14(5):323-328.

16. Selim K, Tsimidou M, Biliaderis CG. Kinetic Studies of Degradation of Saffron Carotenoids Encapsulated in Amorphous Polymer Matrices. Food Chemistry. 2000;71(2):199-206.

17. Rosenberg M, Kopelman IJ, Talmon Y. Factors Affecting Retention in Spray-Drying Microencapsulation of Volatile Materials. Journal of Agricultural and Food Chemistry. 1990;38(5):1288-1294.

18. Rosenberg M, Kopelman IJ. Microencapsulation of Food IngredientsProcesses Applications and Potential. Food Science Technology. 1983;2:142-143.

19. Ramadan MF, Kroh LW, Mörsel JT. Radical Scavenging Activity of Black Cumin (Nigella sativa L.), Coriander (Coriandrum sativum L.), and Niger (Guizotia abyssinica Cass.) Crude Seed Oils and Oil Fractions. Journal of Agricultural and Food Chemistry. 2003;51(24):6961-6969.

20. Velasko J, Holgado F, Dobarganes C, et al. Antioxidant Activity of Added Phenolic Compounds in Freeze-Dried Microencapsulated Sunflower Oil. Journal of the American Oil Chemists Society. 2009;86(5):445-452.

21. Tepe B, Sokmen M, Akpulat HA, et al. Antioxidative Activity of The Essential Oils of Thymus sipyleus subsp. sipyleus var. sipyleus and Thymus sipyleus subsp. sipyleus var. rosulans. Journal of Food Engineering. 2005;66(4):447-454.

22. Yoshida H, Kajimoto G, Emura S. Antioxidant Effects of $d$-Tocopherols at Different Concentrations in Oils during Microwave Heating. Journal of the American Oil Chemists Society. 1993;70(10):989-995.

23. Meyer AS, Heinonen M, Frankel EN. Antioxidant Interactions of Catechin, Cyanidin, Caffeic Acid, Quercetin, and Ellagic Acid on Human LDL Oxidation. Food Chemistry. 1998;61(1-2):71-75.

24. Simonne AH, Eitenmiller RR. Retention of Vitamin E and Added Retiny Palmitate in Selected Vegetable Oils during Deep-Fat Frying and Fried Breaded Products. Journal of Agricultural and Food Chemistry. 1998;46(12):5273-5277.

25. Nesaretnam K, Devasagayam TPA, Singh BB, et al. Influence of palm oil or its tocotrienol-rich fraction on lipid peroxidation potential on rat liver mitochondria and microsomes. Biochemistry and Molecular Biology International. 1993;30(1):159-167.

26. Serbinova E, Kagan V, Han D, et al. Free radical recycling and intramembrane mobility in the antioxidant properties of a-tocopherol and atocotrienol. Free Radic Biol Med. 1991;10(5):263-275.

27. Theriault A, Chao JT, Gapor A, et al. Tocotrienol: A Review of Its Therapeutic Potential. Clin Biochem. 1999;32(5):309-319. 
28. Hoffmann G. The chemistry of edible fats. In: The chemistry and technology of edible oils and fats and their high fat products. London: Academic Press; 1989. p.1-28.

29. Goh SH, Choo YM, Ong ASH. Minor Constituents of Palm Oil. Journal of the American Oil Chemists Society. 1985;62(2):237-240.

30. Shamai K, Shimoni E, Bianco-Peled H. X-Ray Scattering of Resistant Starch Type III. Biomacromolecules. 2004;5(1):219-223.

31. Chandrasekaram $\mathrm{K}, \mathrm{Ng} \mathrm{MH}$, Choo $\mathrm{YM}$, et al. Effect of Storage Temperature on The Stability of Phytonutrients in Palm Concentrates. American Journal of Applied Sciences. 2009;6(3):529-533.

32. Hidalgo A, Brandolini A, Pompei C. Kinetics of Tocols Degradation during the Storage of Einkorn (Triticum monococcum L. ssp. monococcum) and Breadwheat (Triticum aestivum L. ssp. aestivum) Flours. Food Chemistry. 2009;116(4):821-827.

33. Dian NLHM, Sudin N, Yusoff MSA. Characteristics of Microencapsulated Palm-Based Oil as Affected by Type of Wall Material. Journal of the Science of Food and Agriculture. 1996; 70(4):422-426.

34. Robert P, Carlsson RM, Romero N, et al. Stability of Spray-Dried Encapsulated Carotenoid Pigments from Rosa Mosqueta (Rosa rubiginosa) Oleoresin. Journal of the American Oil Chemists Society. 2003;80(11):1115-1120.
35. Widicus WA, Kirk JR, Gregory JF. Storage stability of a-tocophero in a dehydrated model food system containing no fat. Journal of Food Science. 1980;45(4):1015-1018.

36. Chung HY. Oxidative degradation kinetics of tocopherols during heating. Journal of Food Science and Nutrition. 2007;12(2):15-118.

37. Chung HY. Formation kinetic study of thermal products of tocopherols. Journal of Food Science and Nutrition. 2007;12:131-134.

38. Shin TS. Kinetics of antioxidant degradation in rice bran on extruder stabilization processing. Food Science and Biotechnology. 1999;8:4753.

39. İpek U, Arslan EI, Öbek E, et al. Determination of Vitamin Losses and Degradation Kinetics during Composting. Process Biochemistry. 2005;40(2):621-624

40. Lavelli V, Fregapane G, Salvador MD. Effect of Storage on Secoiridoid and Tocopherol Contents and Antioxidant Activity of Monovarietal Extra Virgin Olive Oils. Journal of agricultural and Food Chemistry. 2006;54(8):3002-3007.

41. Gutiérrez F, Fernández JL. Determinant Parameters and Components in the Storage of Virgin Olive Oil. Prediction of Storage Time beyond which The Oil is No Longer of "Extra" Quality. Journal of Agricultural and Food Chemistry. 2002;50(3):571-577. 